\title{
Culture-Led Regeneration in the Post-Industrial Built Environment: Complements and Contradictions in Victory Square, Vancouver
}

\author{
Murray Mckenzie \& Thomas Hutton
}

Published 2015, Journal of Urban Design 20(1), 8-27.

DOI: https://doi.org/10.1080/13574809.2014.974149

\begin{abstract}
$\underline{\text { Abstract }}$
A nuanced discourse on the mix of factors shaping the urban cultural economy includes investigations of the saliency of the built environment, and particularly the positionality of heritage buildings, in cultureled urban regeneration programs. To this enterprise we contribute an assessment of cultural regeneration in Victory Square, an historically rich and socially-contested site at the intersection of Vancouver's Downtown Eastside [DTES] and the Central Business District (CBD), with its long history of marginalization and contemporary trajectory of social upgrading, and the insistently revalorized inner city of new high-rise residential communities. Both the conflictual past and dislocations of the 'active present' insert multiple narratives into the regeneration storyline, underscoring the complexity of social relations played out within the postindustrial landscapes of the city.
\end{abstract}

Key words: culture; heritage landscapes; regeneration; dislocation; Vancouver 
Introduction. The Inner City and Culture-led Regeneration

Processes of industrial innovation and restructuring in the post-Fordist era have contributed to a reshaping of the urban-regional space-economy among both advanced and 'transitional' societies. These experiences include the emergence of technology-based clusters in suburban and exurban zones, shaped in some cases by the proximity of leading research universities, notably Silicon Valley (Stanford University) in northern California, and, in Greater Los Angeles-Orange County (California Institute of Technology), as recounted by Allen Scott in his treatise on Metropolis: From Division of Labor to Urban Form (1988). But over the last two decades or so 'culture' in its diverse and complex forms has contributed to an emergent creative city and economy, encompassing production, consumption and spectacle. In many cases the rise of a 'new cultural economy' shaped by synergies of arts, technology and attributes of place has stimulated the regeneration of obsolescent districts of the postindustrial city, as well as bringing new spaces of the metropolis into play.

The regenerative capacity of the new cultural economy has been best demonstrated within older precincts of the inner city notably characterized by the adaptive reuse of heritage structures, often to the extent of the comprehensive restoration of entire blocks or subareas. The unique material and semiotic characteristics of these dynamic new industrial districts have led to an association of cultural production with a heritage built environment, generating an alluring and paradoxical aesthetic where the brick and iron of an older industrial vernacular mixes with a contemporary aura of technology, globalization and modernity. During the fin-de-siècle New Economy era inner city heritage areas were colonized by dotcoms attracted by an industrial resonance and cheap rents, observed in well-known cases such as Silicon Alley in Manhattan (Indergaard 2004), Clerkenwell in London (Evans 2004), and the South of Market Area (SOMA) in San Francisco (Hutton 2008).

But over the past decade a more complex relayering of capital and space in the inner city has produced upscale housing and consumption amenity as well as cultural production enterprises, along with a more purposeful (if often conflicted) local planning program for adaptive reuse of the heritage built 
environment. While there are to be sure important regeneration experiences to acknowledge, there are also increasingly episodes of displacement in many cities, including both dislocations in situ, as well as spillover effects that are part and parcel of the externalities of redevelopment in the urban core. Here we can cite both the rapid turnover and 'churn' of firms and enterprises associated with appreciably shorter cycles of innovation in the city, as well as the larger backdrop of revalorization shaped both by industrial and social upgrading, as the London and New York examples demonstrate, and as Catungal et al. (2009) have shown in the Liberty Village cultural quarter case in Toronto's Parkdale industrial district.

This paper builds on previous scholarship examining these spatial and material preferences in detail, by interrogating the implications of these (re)constructed imageries in the ongoing transformation of obsolescent industrial landscapes into aestheticized sites of cultural production. Drawing on an ongoing primary research program ${ }^{\mathrm{i}}$ comprising field operation and interviews in Vancouver and other cities and sites, we parse the symbolisms of the Victory Square production district, demonstrating the conflation of historical and mythological sources informing this selective and recombinant place-identity. The most recent interview series, quoted selectively below, was conducted in late 2011 and early 2012 with a number of creative directors representing firms located in Gastown, Victory Square, and Railtown, in Vancouver. Industries represented include design for print and digital (web-based) media, architecture, branding, and video game design.

Following this introduction we rehearse some principal features of how the built environment plays into the rise of a 'new cultural economy' - as a landscape marker of change, as palimpsest for new inscriptions of innovation, and indeed as a motive force for shaping new economic trajectories in the metropolis. Next, we present a discussion of different forms of culture-led urban regeneration, including features which shape change on the ground in cities, and incorporating commentary on the range of outcomes experienced from place to place. We then offer a concise outline of change in Vancouver as context for our Victory Square case study, including the sequence of industrial phases set against larger processes of transformation. Next, in two sections we interrogate signifying features of Victory Square as 
site of culture-led regeneration, first, by offering a description of critical landscape features in the area as a distinctive site within the larger Downtown Eastside (DTES), and then by an account of both the possibilities and limitations of the heritage built environment in the renewal process, always mindful of the delicate balance of interests present within the central city (Ley 1996).

\section{Heritage Districts, Building Typologies and Adaptive Reuse in the Metropolis}

Cities have always functioned in part as centres of creativity and cultural production. In historical terms we need only recall the saliency of artists and designers of genius in the rise of northern Italian cities in the quattrocento, exemplified by da Vinci, Michelangelo, Cellini, and Borromini. In East Asia, as Kong Chong Ho, Won Bae-Kim and Mike Douglas have demonstrated in Culture and the City in East Asia (OUP: 1997), 'culture' has been both a contributing factor and signifier of urban primacy, as seen in the examples of Beijing, Tokyo, Seoul, and Hanoi, among others. The high degree of concentration of power of all kinds (political and military, as well as economic) in the national capitals of East Asia included the deep signifiers of suzerainty, cultural projection and social control, manifestly including iconic buildings and monuments of various kinds, such as imperial palaces and major state buildings. Further, the wealth of the élites of these national primate cities engendered patronage of artists and designers of all kinds, underscoring the association and indeed interdependency between culture, creatives and the city in history (Hall 1998).

This association between cities and culture has assumed in the view of many a new character in the rise of a 'new cultural economy' since the 1980s, both in ostensibly 'advanced' (London, Milan, Chicago) and 'transitional' (Shanghai, Mumbai, Rio de Janeiro, and Istanbul) cities. There is of course a rich and burgeoning literature (or literatures) concerning the causalities of this nascent economic trajectory, including, at one level, an acknowledgement of the enhanced importance of design in the post-Fordist economies of western societies. In the wake of the almost total collapse of traditional, standardized assembly-line manufacturing in western economies, clearly 'design' (incorporating functional as well as 
semiotic attributes) in high-cost jurisdictions is an essential feature of competitive advantage, as industrial production overall continues to shift to the nascent economies of Asia.

But as is well known the principal locus of debate concerns the positionality of cities in the expansion of the cultural economy and the rise of a putative 'creative class'. Without rehearsing this debate in detail, we accept here that Richard Florida's model of a hegemonic 'creative class' shaped by a mix of the 'three Ts' of talent, technology and tolerance, while useful in contributing to a major urban studies discourse, has been effectively critiqued (if not comprehensively repudiated) by Ann Markusen (2006), Allen Scott (2011), Jamie Peck (2005) and Stefan Krätke (2011). These scholars insist on the enduring saliency of capital, agglomeration and labour markets in this as in other moments of urban economic history, and, secondly, urge greater care in specifying creative occupations within large employment fields which necessarily incorporate a high degree of diversity and promiscuity of tasks and functions. Interestingly, Florida has recently backed away from his more exuberant scenarios of creative cities, reflecting to an extent the mixed fortunes of the cultural sector in some cities following the 2008 financial crisis (Indergaard, Pratt and Hutton 2013).

The new cultural economy and the built environment of the city

Major episodes of industrial innovation and economic (and urban) transformation have been accompanied by commensurately large-scale capital relayering, including strategic infrastructural investments and the emergence of new building types and forms. Thus the industrial revolution originating in northern England at the end of the Eighteenth Century and resultant century and a half of development in the industrialization-urbanization nexus produced new landscapes of the 'factory world' and 'industrial city', including sites of fabrication and assembly, as well as ancillary warehousing and distribution (Allen 2009).

The early industrialization experience also produced social correlates in the form of working class housing in cities such as Manchester, Essen, Chicago and Montréal. For many workers and their families 
the industrial city represented a material advance over the deep poverty of rural life, although the polemical work and acute social criticisms of Dickens, Marx, Engels and Zola, among others, should be proof against any tendency to romanticize these industrial congeries, replete as they were with squalor, disease, inequality and oppression. Later, over the last four decades of the twentieth-century the so-called 'postindustrial city' produced new landscapes in urban areas, most notably in the high-rise office tower. Here we acknowledge of course that the office tower as principal building type in the city has its provenance in the original Central Business District of Chicago's Loop district in the 1880s. But it was the dramatic growth of a complex and stratified office workforce (executives, administrators, clerical, sales and technical staff) representative of a new division of labour among advanced societies which stimulated demand for new commercial building development, as well as its social correlate, a 'new middle class' of managers and professionals whose housing preferences shaped new residential landscapes in the city, including successive rounds of social upgrading in the form of gentrification (Hamnett 1991; Ley 1996).

\section{Models of culture-led regeneration in the city}

Before proceeding to our Vancouver case study we review the lineage of this model of urban redevelopment, including the mix of motivations, agencies, actors and instruments involved in each case, and, not least, geographical and scalar considerations. As a first principle we accept that in virtually no cases is 'culture' the sole motivation; there are always political actors and market interests underpinning important programs and experiments. This may be no bad thing itself, as surely political institutions are involved in one way or another in most urban redevelopment ventures, and indeed constructive actions by elected officials and staff can ensure that there are significant public benefits accruing from redevelopment. This point is effectively underscored in a recent volume co-edited by Carl Grodach and Dan Silver titled The Politics of Urban Cultural Policy (2013). Here Grodach and Silver make the point that the last decade or so has seen the increasing 'urbanization' of cultural policy previously conducted principally by the larger state, in response to the larger role of creative industries and labour in the 
postindustrial urban economy, and the corollary expansion of cultural policy as 'an object of governance' at the local level. But the editors (and many of the contributing authors) problematize this tendency by reference to the instrumental use of 'culture' in neo-liberal urban policies designed not to promote public engagement with the arts, nor to expand creative opportunities for collective or individual expression, but rather to compete with other cities for ostensibly footloose capital and skilled labour.

Although the rise of a 'new cultural economy' and putative creative class is frequently seen as a contemporary development, arguably the lineage of 'culture-led redevelopment' can be traced back to much earlier periods, as seen in 'hallmark events' (Olds 2001) such as international expositions and world fairs, which include significant cultural content. These date at least as far back to the 1851 London Exposition which showcased synergiess of industry, industry and arts, and continue to the present day. The same can be said to a degree at least in the Olympic Games, where 'culture' in the form of performance and showcasing national and/regional cultural achievement is increasingly the expectation of IOC adjudicators.

As in other urban economic policy fields 'first-movers' in the domain of culture-led regeneration have greatly influenced both practice and discourse, with Frank Gehry's Guggenheim building in the obsolescent port district of Bilbao (opened 1997) an important example which has generated numerous mimics, as noted by Graeme Evans (2009). Efforts to catalyse regeneration by means of a single, spectacular building continue to form part of the policy repertoire. But increasingly the emphasis is on wider (spatially and thematically) visions and programs involving more comprehensive 'cultural makeovers'. An important example here is the comprehensive redevelopment of the South of Market Area (SOMA) in San Francisco in the last two decades of the twentieth century, a mega-project which included the San Francisco Museum of Modern Art, the Moscone Center, the and the Yerba Buena Center. Notionally at least investments in cultural infrastructure and institutions served to rejuvenate a district of the City which had experienced industrial decline in the postwar period. But property revalorization accruing from these investments, coupled with the well-documented dot.com boom and 
incursion of live-works in the 1990s attracted in part by the aestheticized terrains of SOMA, produced a deeply troubling sequence of dislocations, as recounted by Rebecca Solnit in Hollow City, and continuing a long tradition of capital relayering and displacement rendered in Chester Hartman's masterly volume City for Sale.

We can cite two further cases to elucidate the role of culture in area-based regeneration, drawing on important European examples. First, we can reference the Bermondsey Street conservation program in the London Borough of Southwark, supported by English Heritage and other agencies, in which conservation of an important former warehousing district was intended to attract artists, designers and other cultural actors. In this aim the Bermondsey Street project has been in part at least successful. But with the upgrading of the area's built environment the tentacles of gentrification have now inserted themselves in property after property, insistently shunting artists to the periphery. Second, 'culture' in its manifest forms has been a principal feature of the Biccoca project in north-central Milan, on the former Pirelli Tire site. Following a major process of investment and redevelopment, the area now boasts high-design housing, a campus of the University of Milan, and the striking Teatro Arcimboldi, presenting at first glance a success story of culture-infused regeneration. But as Pier Luigi Sacco and Giorgio Tavano Blessi have observed (2009), the lack of a committed public consultation, outreach and inclusion program has seriously impaired the goal of generating a significant grass-roots artistic dividend from the capital investment in the project.

These prominent examples underscore the increasing centrality of 'culture' in area-based regeneration and community planning across a range of jurisdictions, but disclose as well some of the pitfalls ensuing from the dominant role of capital and political institutions. As artists performing as 'vanguard' or pioneer gentrifiers have been supplanted by more affluent members of the new middle class, so too have small creative enterprises been displaced by more high-margin companies in new rounds of succession, linked in part by property inflation accruing from the aestheticization of urban landscapes and upgrading in each 
of the cases just described. With these examples in mind we now turn to our case study of the Victory Square regeneration program in Vancouver.

\section{Vancouver as Site of Study: Contingency and Exceptionalism}

A concise review of the literature suggests Vancouver represents a particularly instructive case study for an interrogation of culture-led urban regeneration. There are for example several strands of the urban studies discourse which assist in forming an understanding of the multiscalar industrial, social, physical and policy contexts which frame the development trajectory of our case study: Victory Square. In historical terms we can readily acknowledge that Victory Square was established as Vancouver's first banking and commercial core in the early twentieth century, situated as it was just south of the City's central waterfront and railway terminus. Additionally a major retail strip along West Hastings Street emerged at this time, serving the consumption needs of a burgeoning middle class and working class population in East Vancouver and the City's core. Then, and following a familiar urban experience of succession and transition, Victory Square entered a long, slow period of decline, as the core of Vancouver's business, financial and (eventually) retail sectors shifted inexorably uptown in the postwar era. Signature moments in this experience included a new CBD of high-rise office towers hosting financial and business services constructed along an emergent Burrard-Georgia Street axis in the 1970s, and the erosion of department stores along West Hastings, culminating in the closure of the flagship Woodwards department store at Hastings and Abbott in 1993 (Barnes and Hutton 2009).

\section{$\underline{\text { Legacies of change in Vancouver }}$}

Before we proceed to an inquiry into Victory Square's recent regeneration, though, it is important to concisely rehearse other features of Vancouver's growth and change, which larger features place our case study in context. These include, most notably, the transformation of Vancouver's economy from a staples-dominated trajectory for the City's first century of urbanization, comprising a full range of financial, head office, processing and distribution functions allied with British Columbia's resource 
sector, specializing foremost in forestry but including as well substantial mining and fisheries industries. But Vancouver's role as staples core to the provincial periphery entered a period of secular decline in the 1980s (Hutton 1997), following the loss of its head office and intermediate banking roles to larger corporate centres such as Toronto, the relocation of resource processing elsewhere in the region and beyond, and, as a crucial backdrop, structural problems in the provincial resource base (Barnes et al 2011). As a residual of these processes Vancouver's inner city experienced a deep disinvestment and decline over the last two decades of the twentieth century, including Victory Square and the DTES more generally.

But the 1980s also saw the establishment of a new trajectory of urbanization and urbanism for Vancouver, this time associated with a strategic globalization (or at least transnationalism), in the form of inflows of migrants, capital and cultures from the Asia-Pacific, at first principally from Hong Kong, in advance of the reversion of the Crown Colony to China in 1997, and then from a more diverse set of source societies in East and South Asia. As Kris Olds has recounted, this comprehensive reorientation of Vancouver's urbanization pathway included Expo '86, a world's fair convened in 1986 to commemorate the City's first centenary. This event provided a multi-faceted stimulus to Vancouver's emergent transnationalism, as well as paving the way for a new round of investment and capital relayering in Vancouver's core, in the form of the Concord Pacific urban mega-project on the north shore of False Creek (Olds 2001).

The policy context is crucial, too, as the City's approval of the Central Area Plan by City Council in 1991 established new residential development as the preferred choice for land use in the core as a whole, a statement underscored by a strategic rezoning of 'surplus' commercial space in the core to housing, and expressed initially in the City's characterization of housing over commercial development as the 'Living First' program, then more recently as 'Vancouverism' - shorthand for the curtain of point towers with podium platforms which ring the northern edge of False Creek and the Central Waterfront. Demand for new condominium units has been consistently high since the mid-1990s, shaped in part by the local residential market, including migrants from elsewhere in Canada, and by local 'empty-nesters' seeking 
smaller quarters located in amenity-rich communities of the central city. But it seems fair to say that exogenous demand has underpinned the marketing program for the new residential communities over much of the last two decades, reflecting the yawning gap between Vancouver housing prices (the highest in Canada) and labour market incomes in the region (about average for Canadian metropolitan cities). ${ }^{\mathrm{ii}}$

\section{Victory Square and the DTES: from inner city backwater to site of renewal and dislocation}

All this took place some distance from the DTES, emphasizing the area's apparent backwater status in the comprehensive redevelopment of Vancouver's central area. Indeed the (draft) Victory Square Plan (1995) acknowledged a delicate balance of interests between key interests groups in the area, including property owners, heritage advocates, and approximately 1,000 residents of single-occupancy hotels (SROs), all of which suggested an incremental approach to redevelopment. The landscape effects of disinvestment in Victory Square included the derelict storefronts along West Hastings, iii imageries redolent of American rustbelt cities such as Detroit and Cleveland, rather than the glittering 'new inner city' of Vancouver's Concord Pacific and Yaletown, less than a mile to the west.

While Victory Square lay outside the principal zones of redevelopment in the City's core, the area experienced something of a cultural makeover during the 1990s, as represented by the establishment of the Vancouver Film School on Hastings Street, the offices of the Architectural Institute of British Columbia across from the Square itself, and an infiltration of small enterprises such as new media which took up residence in the area's numerous heritage buildings, notably the former Dominion Building at Hastings and Cambie, and the Sun Tower (Barnes and Hutton 2009).

The prospective redevelopment of the (former) Woodward's Department Store site, covering an entire city block (with another block of parking across Cordova Street) was clearly crucial to the area's future. But the redevelopment of the site was constrained to a large extent by political, economic and financial issues. City Council, planners and community activists each evinced concerns about the likely dislocative effects of large-scale development. Developers expressed concerns regarding the feasibility of 
redevelopment in market terms, particularly if the supply of a large number of social housing units, and public space and amenities, were to be stipulated as pre-conditions. Relatedly, heritage advocates worried that a development model considered feasible in market terms would likely result in the demolition of most of the site, with only the original section of Woodward's at the corner of Hastings and Abbott preserved from the wrecker's ball. The compromise reached incorporated the oldest (circa 1903) segment of the structure but replaced most of the block with a mixed-use complex and a landmark high-rise tower (see Figure 3 below) housing 536 condominium units. The redevelopment is impressive to be sure, accommodating as well 200 nonmarket housing units, retail, community services and amenities, nonprofit space and Simon Fraser University's School for the Contemporary Arts, all oriented around a well-used public atrium (see Figure 5 below). But, while celebrated in some circles as a victory of social inclusion, mixed uses and public-private collaboration (Enright 2010), it has been handled more critically by gentrification scholars who object to its neoliberal mechanisms and 'revitalization' rhetoric and see little promise in its efforts to avoid displacement (N. Smith and Derksen 2002; Sommers and Blomley 2002; Blomley 2004; Lees, Slater and Wyly 2008). Without ascribing causality to Woodward's as a singular (albeit comparatively significant) instance of redevelopment, it is evidently associated with a general centripetal flow of reinvestment into Victory Square, including restaurants, boutique retail, further condominium development and, to be sure, creative studios and agencies.

As for the contested politics of property and identity on the DTES, however, Woodward's has been Vancouver's beacon for conflict par excellence, the product of a protracted and highly-politicized process of negotiation and planning since the department store's closure in 1993. The symbolic significance of debates and activism surrounding the Woodward's redevelopment have been explored in detail elsewhere (eg, Blomley 2004, 39-46; Pell 2008; 2012), but we point to it here as an introduction to the following discussion on the complex legacy of contestation in Victory Square. While legal ownership of the site was held by the provincial and then municipal governments, who sought to establish a public-private development partnership, DTES community members (including a significant contingent of antipoverty activists) endeavoured to demonstrate their own claims to the space through a series of symbolic actions 
including voluntarily maintaining the site and decorating it with anti-displacement slogans and cheerful

images. Subsequently, a large protest encampment was set up on surrounding streets and squatters entered the building to be forcefully evicted by police in late 2002 . These actions demonstrate the competing notions of ownership at stake, echoed in competing interpretations of the department store's historical significance, alternately framed as a symbol of an era before social problems became the dominant DTES narrative (Thompson 2002) or as the very symbol of the area's decline itself (Sommers and Blomley 2002). While the rebranding of the site necessarily relied on a reasonably sanitized nostalgia and a rather optimistic reinterpretation of the development's social significance (Proudfoot 2011), it also symbolically gifted the redevelopment to the creative class: "this is intellectual property" read the marketing slogan in 2006 (quoted in Hutton 2008, 252). ${ }^{\text {iv }}$

\section{Inscriptions of Culture and Contestation in Victory Square}

A survey of the distribution of aesthetically creative firms in Vancouver's inner city fringe discloses the salience of a heritage built environment as a geographical determinant in local narratives of culture-led regeneration (Figure 1). But relative to Yaletown and Gastown, two high-integrity heritage areas comprising late-nineteenth century warehousing districts, Victory Square presents an altogether more stylistically and typologically variegated heritage landscape. The impression given by its ensemble of narrow-frontage commercial and institutional buildings is of a finely-textured urbanism; the degree and variety of their elaborate architectural ornamentation distinguishes the built environment from the more austere industrial heritage found elsewhere (Figures 2a and $\mathbf{2 b}$ ). The district is punctuated by a number of landmark taller buildings, including Woodward's and a handful of prestigious Edwardian-era office towers that have served emblematic roles similar to that of the Flatiron building in Manhattan's Silicon Alley (see Indergaard 2004) (Figure 3). The success these older office buildings have had when adapted for creative work presents something of a counterpoint to the well-known literature on loft conversions (eg, Zukin 1982; Hamnett and Whitelegg 2007), for, while they too boast the high ceilings, ample natural light and large, operable windows for which industrial lofts are prized, they are also distinguished by a 
heightened degree of architectural detail and internal spatial configurations suitable for a large number of small firms. ${ }^{v}$

Figure 1. Distribution of firms for select industries and Vancouver's Heritage Areas. Source: Authors' Survey (2012).

Figures 2a and 2b. Finely-textured urbanism and Victory Square's varied architectural ensemble.

Figure 3. Landmark tall buildings overlooking the Victory Square cenotaph: the Dominion Building (1910) and the Woodward's redevelopment (2010).

Built environment notwithstanding, however, the predominant imageries of Victory Square are rooted in entangled strands of contestation that are both resistant to and propelled by insistent gentrification pressure. Foremost among these strands is the pressing substance abuse and mental illness problems focused in the DTES. Contestation over these is enacted spatially in social housing advocacy and an increasingly resolute and combative community resistance to dislocation. But this is only the present iteration of the "mythical tradition of conflict" (Ley and Dobson 2008, 2483) here, which has been traced in terms of shifting representations of vice and vagrancy as far as back as the earliest resource economy downturns of the 1940s (eg, Hasson and Ley 1994; Sommers 1998; Sommers and Blomley 2002; Proudfoot 2011; Liu and Blomley 2013). Victory Square has a legacy as a locus for class struggle that also takes in organized labour protests and a police riot (1935) in depression-era Vancouver, postwar 'skid row' rhetoric lodged at the community of retired male resource workers culminating in urban renewal debates of the 1960s, and the often-heated anti-poverty activism led by the Downtown Eastside Residents' Association [DERA] from the 1970s onwards. The square itself has often served as an epicentre of protest, and the spirit of resistance was also preserved by the dedicated anti-Capitalism of the Spartacus bookstore until its relocation due to fire in 2004.

But another strand of contestation, sitting uncomfortably with the others, exists in the form of a resilient bohemianism that finds its origins in the countercultural movements of the 1960s. David Ley's (1996) influential analysis of artist-led gentrification was based on his observations in Victory Square and Gastown of the hippy community that expressed the aesthetic disposition, liberal politics, and preference 
for inner city locations that anticipated the postindustrial middle-class. The countercultural claim on space was not achieved without the navigation of a tumultuous cultural politics, highlighted by the Gastown Riot of 1971, triggered by a police raid on a 'smoke-in'. The heritage preservation advocacy that 'saved' present-day Gastown was founded, shortly after the riot, on an explicit anti-countercultural rhetoric (Denhez 1978), but it was never able to realize its deeper social aim. Amidst the ongoing countercultural practices in Victory Square, the spirit of the 1960s is preserved by the lasting presence of the BC Marijuana Party Offices and the Amsterdam Café, both on the square.

Contestation is negotiated in aesthetic terms as the constituent actors strive to assert their own influence on the reimaging process. In the Gastown Heritage Area, overprescribed preservation policy has received criticism for its theme-park-like reimagination of history, including 'heritage' brick paving, cast-iron street furniture, faux-Victorian globe street lamps and, most controversial of all, the faux-Victorian steam clock (Punter 2003) (Figure 4). This has served to push the more troubling social issues south into Victory Square. The preservationist vision for Gastown, including the maintenance of a "turn of the century" architectural character (City of Vancouver 2010b, 1) and the requirement that all changes "bring heritage buildings closer to their original exterior appearance" (City of Vancouver 2002, 2), promotes a radical decontextualization and denial of the contestation legacy that undermines the capacity of marginalized social groups to make a claim on space. If imported into Victory Square, this exclusionary preservation vision would be dissonant with the goal of the Victory Square Policy Plan (City of Vancouver 2005) for high-integrity preservation without dislocation, given its suppression of the hybridity and diversity of public history. On a better note, the installation of a large-scale photographic recreation of the Gastown Riot in the Woodward's atrium, by renowned local conceptualist photographer Stan Douglas, preserves the role of conflict in collective remembrance and resists Vancouver's attempts to incorporate only ideal images of itself (Oleksijczuk 2002) (Figure 5).

Figure 4. Preservation and beautification on Maple Tree Square, site of the Gastown Riot.

Figure 5. The remembrance of contestation: Stan Douglas's Abbott \& Cordova, 7 August 1971 (2009) in the Woodward's atrium. 


\section{Culture-led reimaging and the resignification of Victory Square}

The ascendance of the new cultural economy in Victory Square has promoted a relayering of the palimpsestic accumulation of imageries associated with the shifting fortunes of the local area. While we

can interpret this in one sense as a reaffirmation of the inner city's industrial capacity, at another level we can acknowledge an inversion of symbolisms in the district's industrial and commercial built

environment. Where the new socio-spatial formations associated with the cultural economy are inserted into the built forms of the old industrial economy, we can observe a resignification of spaces of social control as spaces of creative freedom (Hutton 2006) - and this is echoed by the creative director of a design studio who describes the "workingman's philosophy" that governs their non-hierarchical and relatively unstructured workspace (personal interview 2012). But in Victory Square we can also point to the resignification of the heritage built environment, otherwise commemorative of commercial prestige and ambition, as instead representative of authentic and colourful urbanism and innovative and avantgarde cultural forms.

Victory Square's role as a site of social contestation is threatened by the gentrification pressures attendant on culture-led regeneration, for with regeneration comes not only revalorization and redevelopment but also a reimaging process that threatens to occlude alternative claims on space. Those who lead the ascendance of cultural production may demonstrate social insensitivity. Scholars such as Harris (2012) have commented on the tendency for artistically-inclined gentrifiers to cultivate a detached appreciation of the signifiers of marginalized populations as somehow emblematic of a more authentic urbanism, but with a limited transgressive capacity: the desire is for "not as much of that undesirable element, but still enough of it to keep it interesting" (personal interview 2012). Bain (2003) and Lloyd (2006), although more concerned with artistic and bohemian communities respectively, point to the mythology of the creative 'outsider' that motivates a migration to the marginal and grittier landscapes of the urban fringe in search of personal and creative freedom. To some degree these attitudes are conditioned by sociallyconstructed expectations, particularly those of potential clients who are likely to look for creative firms in 
specific fringe areas and demand of them a characteristic look and feel. As one designer states, 'creatives' are "held to a little bit of a higher level" (personal interview 2011). The mere perception that Victory Square offers cheaper commercial space, another designer explained, is attractive to clients because it suggests lower overhead and therefore lower rates to be paid for creative services.

\section{The Possibilities and Limitations of a Heritage Built Environment}

The Victory Square Policy Plan proposes a vision that unites the critical landscape features we have identified in the district: heritage revitalization and conservation, social housing provision and 'revitalization without displacement', and arts- and culture-led regeneration. To what degree is this attainable, and what lessons can we distill for further critical policy analysis? Figure 6 depicts the interspersion of these constituent elements, and indicates the eastward drift of dislocation pressure. From among a creative cities policy suite that also includes business support services, grants and loans, fiscal/tax schemes and 'soft' infrastructure (Evans 2009), the Vancouver case points to the key role of land use planning, heritage preservation policy and urban design guidelines for the exceptional influence they have had on determining the geography of the cultural economy in the central area. The prescriptions of the Central Area Plan (City of Vancouver 1991) still comprise the most salient policy initiative enabling the rise of a new economy of cultural production in a reconfigured metropolitan core accomplished via a preference for 'industrial character', the designation of mixed-use areas, and the confirmation of heritage district designations for emergent production sites (Hutton 2004; 2008). But more specific and deliberate public realm initiatives are now necessary at the neighbourhood scale as the Victory Square plan moves out of its 12-year gestation period and into the implementation phase. Successful intervention will require considerable sensitivity to the precarious balance of stakeholder interests and policy goals.

Figure 6. The interspersion of the cultural economy, heritage preservation and low income housing in Victory Square.

Sources: Authors' survey (2012) and City of Vancouver (2005; 2010a). 
Planning must acknowledge the gentrification pressures posed by heritage revitalization or beautification schemes, which were, for example, pivotal in the Gastown gentrification narrative (Ley 1996). The provision of financial incentives for rehabilitation or restoration is a means of re-capitalization that is likely to increase the rents that can be realized from a given building in its improved state; furthermore, in many cases, even the mere conferral of heritage designation is capable of raising property values (Shipley 2000). Heritage designation has also accelerated intra-district polarization by either necessitating the sustainment of economic vitality, such that high costs of further maintenance and conversions can be met (eg, in Gastown), or, conversely, by encouraging disinvestment and the deferral of maintenance where the economics of rehabilitation are not yet feasible (eg, on the eastern fringe of Victory Square and further into the DTES) (H.A. Smith 2003). Clearly, there are trade-offs that must be mitigated. In the 'Vancouverism' planning model - where heritage preservation, replacement low-cost housing and arts and cultural space are among the range of public amenities that may be leveraged on a case-by-case basis from developers at the permit application stage of redevelopment (see Punter 2003) - the pursuit of any social or cultural amenities requires careful prioritization and poses an insistent pressure for redevelopment that is not easily reconciled with the desire for incremental change. Recent antigentrification protests (see Bula 2013) have at times highlighted the contention between anti-poverty activists and arts and cultural workers, although both could be united by the shared threat of losing space to condominium conversions. Too often, heritage-led regeneration displaces the very individuals, groups, and social practices that made the district worth saving.

Creativity, politics and the palimpsestic urban landscape

The roles of spatial and material settings and their attendant imageries and semiotics in creative processes have been highlighted by a number of scholars, including Ilse Helbrecht (1998), who describes the 'aesthetic curiosity' that depends on the 'look and feel' of urban places: individuals must "choose those locations and spatial settings that will foster, enhance and unleash their creativity" (8). Likewise, for Graham Drake (2003), the subjective, personal and emotional response to the locality as imagined or 
constructed provides a resource of prompts and symbols that stimulate and nourish creative work. Creativity tends to fall into dialogue with local reputations and traditions, albeit modified by technological innovations and newly attuned to global markets and the spectacle of consumer experience. $^{\mathrm{vi}}$

The importance of heritage imageries in this regard is clear. But what we wish to point out, based on our case-study observations, is the specific appeal of the palimpsestic and multivalent qualities of the accreted imageries we find there. It is the unintentional new meanings suggested by the disorderly and happenstance juxtaposition of imageries - not the unambiguous didacticism of conventional preservation approaches - that provides fuel for the creative fire and encourages the clustering of cultural firms. ${ }^{\text {vii }}$ Designers seek out "colouful people, colourful language, colourful everything" in the neighbourhood and detect "a level of anarchy" in Victory Square that is conducive to their creative work (personal interviews, 2011). Accumulated history contributes to these perceptions:

[I] never want to see it completely polished ... I think as soon as they put a veneer over it it's gonna lose that charm that it has, which is that history ... it's been built up over time. And it's adapted with the times, and it hasn't hidden it. It ... wears it on its sleeve. (personal interview 2011)

When conventional preservation collapses the present into a desired past - by sifting out the intermediate temporal layers - the built environment is likely to lose its fertility as a creative space.

A more palimpsestic and multivalent heritage landscape is likely to contribute positively to the pressing social issues in Victory Square as well that are otherwise threatened by a displacement reflected in the creeping upscale imageries of luxury condominiums, gourmet cuisine and boutique retailers. We can, of course, acknowledge a broad literature on the pursuit of social justice via a more culturally inclusive preservation perspective (eg, Lee 1987; Hayden 1995; Dubrow and Goodman 2003; Kaufman 2009). In Victory Square, social representations are paramount, as we suggested above in our discussion of the Woodward's redevelopment. Portrayals of the 100-block of West Hastings, along the southern edge of the Woodward's redevelopment, as 'the worst block in Vancouver' set in motion the 'urban frontier' rhetoric 
described by Neil Smith (1996) where the ownership of space is up for grabs and the district is ripe for resettlement. But furthermore, as Jeff Sommers and Nicholas Blomley (2002) have argued, the rhetoric of 'heritage' implicitly anchors its value in the district's architectural ensemble, rather than in the legacy of social and political practices this ensemble embodies. The content of collective memory is of premier importance in the legitimation of alternative claims on space (Alderman and Inwood 2013).

Socially inclusive culture-led regeneration should, therefore, include some consideration of the underlying political significance of heritage preservation and the reimaging process. To do so would be to harness the potential of culture to redefine place via its capacity to forcefully inject place and memory into product (see Molotch 1996; 2002). Culture amplifies the imageries and meanings of place, as there will tend to be "powerful and recursively intertwined relations between the meanings that adhere to the urban landscape and the symbologies of the goods and services produced in the local area" (Scott 2001, 17). Cultural producers are attracted to sites offering authentic and stimulating urbanism, and are, to some extent, sensitive to the social and political significance of urban space as well. Furthermore, drawing on the prescriptions of Andrew Harris and Louis Moreno (2012) for a new critical perspective on the cultural economy, local interventions can involve a much more socially-inclusive range of 'creative' practitioners and a much broader definition of what constitutes 'cultural' practice. The task of identifying and celebrating alternative histories signified in the built environment can itself be a creative and inclusive one, and these can be reinforced in community arts and culture projects that interact with and are supported by the conventionally-defined cultural economy. The fleeting Great Beginnings public realm enhancement project, for example, offered DTES community members seed capital to pursue schemes, such as small-scale façade restoration and public artworks, that would strengthen the pluralistic identity of the neighbourhood (City of Vancouver 2010c). But the lasting impact of this three-year project, for which funding support expired in 2010, was limited by the ephemeral and performance-based nature of many of its cultural 'interventions', and was overshadowed by the more imposing redevelopment pressures here that appear to be the most salient legacy of Vancouver's 2010 Winter Olympics. 


\section{Conclusion: Culture, Politics and Meaning in Urban Regeneration}

In this paper we have been concerned with the role of the heritage built environment as an active agent in the culture-led regeneration of Vancouver's DTES, with special reference to the critical Victory Square district. Victory Square's value as site of study is derived in some part from its strategic positioning at the intersection of the western end of the DTES and the downtown 'proper', the latter with its high-rise commercial complex and new condominium communities. But apart from these important geographical reference points Victory Square embodies its own historical narratives and built environment - aspects valued by creative workers across a range of industries, in some cases overtly, and in others in a perhaps more subliminal form.

Victory Square by no means fits the cozy stereotype of a self-contained, fully-localized cultural quarter of easily accessible amenity, available to all, but instead projects imageries and experiences of contestation, exclusion and displacement. The current redevelopment cycle in Victory Square dating from the reconstruction of the iconic Woodward's site does include significant public housing, but its very scale, and substantial market housing and retail uses, inject a forceful dislocation tendency. And, as we acknowledged, the site itself comprises part of the record of public disorder and dislocation, as expressed in the work of Stan Douglas and others. Thus we were concerned to acknowledge a principal disconnect between the 'silent heritage' of the built environment, and its apparent status as a public commodity which can be experienced and appreciated by all, on the one hand; and, on the other, a far more viscerally conflictual social history. Here we draw an analogy of sorts between Victory Square and the Clerkenwell district of London, with the latter increasingly the preserve of élite creatives and upscale residents, assuredly including 'new gentrifiers', occluding to a large degree Clerkenwell's long history as site of political radicalism and social insurrection. And here we acknowledge that while scholarly treatments of both the regenerative and dislocative effects of cultural development programs have tended to emphasise experiences in world cities such as New York, London and Milan, a broader range of medium-size cities can also figure in and enrich the narrative, as the Vancouver case demonstrates. The larger lesson is that 
in cities such as Vancouver which embody an extended history of social upgrading, and a more recent record of mega-projects, processes of capital relayering associated with culture-led redevelopment are likely to accelerate displacement unless significant resources are directed both to community-housing and inclusive arts programming.

We also argue that contingency matters, at various scales. While Victory Square is physically part of the DTES, it offers quite different physical imageries and semiotic values than other subareas of the DTES, including Chinatown, Strathcona, and the nascent cultural regeneration site of Railtown (Mckenzie 2013). And at the broader municipal scale, we acknowledge the deep conflicts between those striving to preserve both the heritage built environment and vibrant social histories of Vancouver, and the larger reality of insistent capital relayering over the last thirty years which places little value on artifacts of the City's past. In this larger context perhaps Vancouver offers something to those who are committed to exploring the fissures and contradictions between cities as repositories of history - and, alternatively, as places constantly in the remaking.

${ }^{\mathrm{i}}$ This paper draws on over a decade of fieldwork on key inner city sites in Vancouver (Yaletown, Gastown, Victory Square and Railtown), as well as comparative work in London (Hoxton, Clerkenwell and Shoreditch), San Francisco (South Parket and SOMA), Singapore (Telok Ayer), Seattle (South Lake Union) and elsewhere. This has entailed (1) key-informant interviews, including academics, planners and policymakers, and representatives of nongovermental organizations; (2) survey and iterative mapping of new industry sites; (3) interviews with representatives of selected firms within key industries (principals, directors, and creative professionals); (4) review of planning and policy documents and other textual sources; and (5) photography of relevant sites and buildings. The marked experiences of gentrification and dislocation in the Vancouver storyline have been taken up in a considerable body of scholarly literature, much of it cited here; the present paper draws heavily on our attempts to think across the interstices between this and local cultural economy scholarship.

ii Internal, inter-regional migration has historically underpinned population growth in Canada's metropolitan cities. But for Toronto (Canada's global city) and Vancouver (which has emerged as an exemplar of the transnational city), inflation in residential markets tends to discourage migration from smaller centres within Canada, and thereby increasing the influence of foreign capital and immigration. See in this regard Larry Bourne et al (eds.), Canada's Urban Regions: Trajectories of Growth and Change (OUP: 2011), especially Chapters 1-3.

iii The state of commercial decline on this strip was recorded in a composite photograph, Every Building on 100 West Hastings (2001), by photographer Stan Douglas. We can observe boarded-up storefronts, a 
pawnshop and convenience stores in Douglas's image, but the pace and degree of change since the reopening of Woodward's are remarkable. On a recent site visit, we observed a salon/spa, two upscale restaurants, fashion apparel retailers, a high-end baby furniture and accessories retailer and the Vancouver Film School.

iv Similar language is employed in the marketing of the Sun Tower, one of Victory Square's heritage landmarks. "This is not office space," the website boasts. "This is creative space."

(suntowerbuilding.com)

${ }^{v}$ These insights are inspired by Carol Willis (1995), who has investigated how market formulas informed by speculative development and structural, technological and regulatory limitations determined the form of early office towers in New York and Chicago. In particular, we can acknowledge the attraction creative workers have to structures predating the mass adoption of air conditioning (1930s) and fluorescent lighting (1940s) and untouched by the changing postwar spatial needs of firms employing larger clerical staffs and larger technological apparatuses.

vi This is the basis of Graeme Evans's (2004) 'cultural industry quarters', described as "an anachronistic hangover from traditional craft, cooperative and place-based manufacturing, but at the same time a renewed landscape in contemporary art, new media and advanced services production" (72). A similar argument, of course, runs through the work of Allen Scott on the privileged urban places that serve as the loci of the cultural economy (see Scott 1997).

vii This argument is inspired by Tim Edensor's (2005) analysis of the creative appeal of Britain's industrial ruins. 


\section{References}

Alderman, Derek H. and Joshua F.J. Inwood. 2013. "Landscapes of memory and socially just futures.” In The Wiley-Blackwell Companion to Cultural Geography, edited by Nuala C. Johnson, Richard H. Schein, and Jamie Winders, 186-197. Malden: Wiley-Blackwell.

Allen, Robert C. 2009. The British Industrial Revolution in Global Perspective. Cambridge: Cambridge University Press.

Bain, Allison L. 2003. "Constructing Contemporary Artistic Identities in Toronto Neighbourhoods." The Canadian Geographer 47 (3): 303-317.

Barnes, Trevor and Thomas A. Hutton. 2009. "Situating the New Economy: Contingencies of Regeneration and Dislocation in Vancouver's Inner City." Urban Studies 46 (5 \& 6):1247-69.

Barnes, Trevor, Hutton, Thomas, Ley, David and Moos, Markus. 2011. "Vancouver: Restructuring Narratives in the Transnational Metropolis", chapter 12 in: Larry Bourne, Thomas Hutton, Richard Shearmur and Jim Simmons (eds.) Canadian Urban Regions: Trajectories of Growth and Change. Toronto: Oxford University Press.

Blomley, Nicholas. 2004. Unsettling the City: Urban Land and the Politics of Property. London: Routledge.

Bula, Frances. 2013. "Pidgin Protests in Downtown Eastside Concern Activist Funders." The Globe and Mail, April 29.

City of Vancouver. 1991. Central Area Plan: Goals and Land Use Policy. Vancouver: City of Vancouver.

City of Vancouver. 1995. Draft Victory Square Policy Plan. Vancouver: City of Vancouver Planning Department, Central Area Division.

City of Vancouver. 2002. HA-2 District Schedule (Gastown Historic Area). Vancouver: City of Vancouver. http://vancouver.ca/files/cov/Gastown-historic-area-HA-2-Schedule.pdf

City of Vancouver. 2005. Victory Square Policy Plan. Vancouver: City of Vancouver. http://vancouver.ca/files/cov/Victory-Square-Policy-Plan-2005.pdf

City of Vancouver, 2010a. 2009 Survey of Low-Income Housing in the Downtown Core. Vancouver: City of Vancouver. http://vancouver.ca/docs/policy/housing-2009-low-income-survey.pdf

City of Vancouver. 2010b. Gastown HA-2 Design Guidelines. Vancouver: City of Vancouver. http://vancouver.ca/files/cov/Gastown-HA2-Design-Guidelines.pdf

City of Vancouver. 2010c. Great Beginnings Program: 2010 Year-End Progress Report. Vancouver: City of Vancouver. http://vancouver.ca/files/cov/great-beginnings-2010-year-end-report.pdf

Denhez, Marc. 1978. Heritage Fights Back. Ottawa: Heritage Canada. 
Drake, Graham. 2003. " 'This Place Gives Me Space': Place and Creativity in the Creative Industries.” Geoforum 34: 511-524.

Dubrow, Gail Lee, and Jennifer B. Goodman, eds. 2003. Restoring Women's History Through Historic Preservation. Baltimore: Johns Hopkins University Press.

Edensor, Tim. 2005. Industrial Ruins: Space, Aesthetics and Materiality. Oxford: Berg.

Enright, Robert, ed. 2010. Body Heat: The Story of the Woodward's Redevelopment. Vancouver: BlueImprint.

Evans, Graeme. 2004. “Cultural Industry Quarters: From Pre-Industrial to Post-Industrial Production.” In City of Quarters: Urban Villages in the Contemporary City, edited by David Bell and Mark Jayne, 7191. Aldershot: Ashgate.

Evans, Graeme. 2009. "Creative Cities, Creative Spaces and Urban Policy.” Urban Studies 46 (5\&6): 1003-1040.

Grodach, Carl and Dan Silver. Eds. 2013. The Politics of Urban Cultural Policy. Abingdon UK and New York: Routledge.

Hall, Peter. 1998. Cities in Civilisation. London: Weidenfeld \& Nicolson.

Hamnett, Chris. 1991. "The Blind Men and the Elephant: Toward a Theory of Gentrification." Transactions of the Institute of British Geographers 16: 173-189.

Hamnett, Chris, and Drew Whitelegg. 2007. "Loft Conversion and Gentrification in London: From Industrial to Postindustrial Land Use." Environment and Planning A 39: 106-124.

Harris, Andrew. 2012. "Art and Gentrification: Pursuing the Urban Pastoral in Hoxton, London." Transactions of the Institute of British Geographers 37 (2): 226-241.

Harris, Andrew, and Louis Moreno. 2012. Creative City Limits: Urban Cultural Economy in a New Era of Austerity. London: University College London. http://www.ucl.ac.uk/urbanlab/news/urbanlab/docs/creativecitylimits

Hartman, Chester. [with S. Carnochan] 2002. City for Sale: The Transformation of San Francisco. Berkeley, CA: The University of California Press.

Hasson, Shlomo, and David Ley. 1994. Neighbourhood Organizations and the Welfare State. Toronto: University of Toronto Press.

Hayden, Dolores. 1995. The Power of Place: Urban Landscapes as Public History. Cambridge: MIT Press.

Helbrecht, Ilse. 1998. "The Creative Metropolis: Services, Symbols and Spaces.” Paper presented at the Jahrestagung der Gesellscahft für Kanada-Studien, Grainau, 1998.

Hutton, Thomas A. 1997. “The Innisian Core-Periphery Revisited: Vancouver's Changing Relationships with British Columbia’s Staple Economy.” BC Studies 113: 69-100. 
Hutton, Thomas A. 2004. "Post-Industrialism, Post-Modernism, and the Reproduction of Vancouver's Central Area: Retheorising the 21 $1^{\text {st }}$-Century City." Urban Studies 41 (10): 1952-1982.

Hutton, Thomas A. 2006. "Spatiality, Built-Form, and Creative Industry Development in the Inner City." Environment and Planning A 38: 1819-1841.

Hutton, Thomas A. 2008. The New Economy of the Inner City: Restructuring, Regeneration and Dislocation in the Twenty-First Century Metropolis. London: Routledge.

Indergaard, Michael. 2004. Silicon Alley: The Rise and Fall of a New Media District. London: Routledge.

Indergaard, Michael, Andy C. Pratt and Thomas A. Hutton. 2013. "Creative Cities after the Fall of Finance." Cities 33: 1-4.

Kaufmann, Ned. 2009. Place, Race, and Story: Essays on the Past and Future of Historic Preservation. London: Routledge.

Kim, Won Bae, Mike Douglass, Sang-Chuel Choe and Kong Chong Ho. 1997. Culture and the City in East Asia. Oxford: Oxford University Press.

Krätke, Stefan. 2011. The Creative Capital of Cities: Interactive Knowledge Creation and the Urbanization Economies of Innovation. London: Blackwell-Wiley.

Lee, Antoinette J. 1987. "Discovering Old Cultures in the New World: The Role of Ethnicity." In The American Mosaic: Preserving a Nation's Heritage, edited by Robert E. Stipe and Antoinette J. Lee, 180-205. Washington: U.S./ICOMOS.

Lees, Loretta, Tom Slater and Elvin Wyly. 2008. Gentrification. London: Routledge.

Ley, David. 1996. The New Middle Class and the Remaking of the Central City. Oxford: Oxford University Press.

Ley, David, and Cory Dobson. 2008. “Are There Limits to Gentrification? The Contexts of Impeded Gentrification in Vancouver." Urban Studies 45 (12): 2471-2498.

Liu, Sikee, and Nicholas Blomley. 2013. "Making News and Making Space: Framing Vancouver's Downtown Eastside." The Canadian Geographer 57 (2): 119-132.

Lloyd, Richard. 2006. Neo-Bohemia: Art and Commerce in the Postindustrial City. London: Routledge.

Mckenzie, Murray. 2013. (Re)Remembering the Inner City: Cultural Production, Reflexivity, and Vancouver's Heritage Areas. Unpublished Masters thesis, School of Community \& Regional Planning, University of British Columbia.

Molotch, Harvey. 1996. "L.A. as Design Product: How Art Works in a Regional Economy." In The City: Los Angeles and Urban Theory at the End of the Twentieth Century, edited by Allen J. Scott and Edward W. Soja, 225-275. Berkeley: University of California Press.

Molotch, Harvey. 2002. "Place in Product." International Journal of Urban and Regional Research 26 (4): 665-688. 
Olds, Kris. 2001. Globalization and Urban Change: Capital, Culture, and Asia-Pacific Mega-Projects. Oxford: Oxford University Press.

Oleksijczuk, Denise Blake. 2002. "Haunted Spaces.” In Stan Douglas: Every Building on 100 West Hastings, edited by Reid Shier, 96-116. Vancouver: Arsenal Pulp Press.

Pell, Susan. 2008. "Making Citizenship Public: Identities, Practices, and Rights at Woodsquat." Citizenship Studies 12 (2): 143-156.

Pell, Susan. 2012. "Mobilizing Urban Publics, Imagining Democratic Possibilities: Reading the Politics of Urban Redevelopment in Discourses of Gentrification and Revitalization." Cultural Studies. http://dx.doi.org/10.1080/09502386.2012.748816

Proudfoot, Jesse. 2011. "The Derelict, the Deserving Poor, and the Lumpen: A History of the Politics of Representation in the Downtown Eastside." In Stan Douglas: Abbott \& Cordova, 7 August 1971, 88105. Vancouver: Arsenal Pulp Press.

Punter, John. 2003. The Vancouver Achievement: Urban Planning and Design. Vancouver: UBC Press.

Scott, Allen J. 1988. Metropolis: from the Division of labor to Urban Form. Berkeley and Los Angeles: University of California Press.

Scott, Allen J. 1997. “The Cultural Economy of Cities.” International Journal of Urban and Regional Research 21: 323-339.

Scott, Allen J. 2001. "Capitalism, Cities, and the Production of Symbolic Forms." Transactions of the Institute of British Geographers 26 (1): 11-23.

Scott, Allen J. (2011). Social Economy of the Metropolis: Cognitive-Cultural Capitalism and the Global Resurgence of Cities. Oxford: Oxford University Press.

Shipley, Robert. 2000. “Heritage Designation and Property Values: Is There an Effect?” The International Journal of Heritage Studies 6 (1): 83-100.

Smith, Heather A. 2003. "Planning, Policy and Polarisation in Vancouver's Downtown Eastside." Tijdschrift voor Economische en Sociale Geografie 94 (4): 496-509.

Smith, Neil. 1996. The New Urban Frontier: Gentrification and the Revanchist City. London: Routledge.

Smith, Neil and Jeff Derksen. 2002. "Urban Regeneration: Gentrification as Global Urban Strategy.” In Stan Douglas: Every Building on 100 West Hastings, edited by Reid Shier, 62-92. Vancouver: Arsenal Pulp Press.

Solnit, Rebecca. [with Susan Schwartzenberg] Hollow City" The Siege of San Francisco and the Crsis of American Urbanism. London and New York: Verso.

Sommers, Jeff. 1998. "Men at the Margin: Masculinity and Space in Downtown Vancouver, 1950-1986." Urban Geography 19 (4): 287-310. 
Sommers, Jeff, and Nicholas Blomley. 2002. "The Worst Block in Vancouver.” In Stan Douglas: Every Building on 100 West Hastings, edited by Reid Shier, 18-58. Vancouver: Arsenal Pulp Press.

Thompson, Lindsay. 2005. The Social Life of Things: A Case Study of the Woodward's Department Store. Unpublished Masters thesis, Department of Anthropology, University of British Columbia.

Willis, Carol. 1995. Form Follows Finance: Skyscrapers and Skylines in New York and Chicago. New York: Princeton Architectural Press.

Zukin, Sharon. 1982. Loft Living: Culture and Capital in Urban Change. New Brunswick: Rutgers University Press. 